\title{
Inhibitory effect of zingiber officinale towards Streptococcus mutans virulence and caries development: in vitro and in vivo studies
}

\author{
Sadaf Hasan, Mohd Danishuddin and Asad U Khan ${ }^{*}$
}

\begin{abstract}
Background: Streptococcus mutans is known as a key causative agent of dental caries. It metabolizes dietary carbohydrate to produce acids which reduce the environmental pH leading to tooth demineralization. The ability of this bacterium to tolerate acids coupled with acid production, allows its effective colonization in the oral cavity leading to the establishment of highly cariogenic plaque. For this reason, S. mutans is the only bacterium found in significantly higher numbers than other bacteria in the dental plaque. The aim of this study was to evaluate the effect of crude extract and methanolic fraction of $Z$. officinale against $S$. mutans virulence properties.

Results: We investigated in vitro and in vivo activity of crude extract and methanolic fraction at sub- MIC levels against cariogenic properties of $S$. mutans. We found that these extracts strongly inhibited a variety of virulence properties which are critical for its pathogenesis. The biofilm formation in S. mutans was found to be reduced during critical growth phases. Furthermore, the glucan synthesis and adherence was also found to be inhibited. Nevertheless, the insoluble glucan synthesis and sucrose dependent adherence were apparently more reduced as compared to soluble glucan synthesis and sucrose- independent adherence. Biofilm architecture inspected with the help of confocal and scanning electron microscopy, showed dispersion of cells in the treated group as compared to the control. The Quantitative Real Time PCR (qRT-PCR) data had shown the down regulation of the virulence genes, which is believed to be one of the major reasons responsible for the observed reduction in the virulence properties. The incredible reduction of caries development was found in treated group of rats as compared to the untreated group which further validate our in vitro data.

Conclusion: The whole study concludes a prospective role of crude extract and methanolic fraction of $Z$. officinale in targeting complete array of cariogenic properties of $S$. mutans, thus reducing its pathogenesis. Hence, it may be strongly proposed as a putative anti- cariogenic agent.
\end{abstract}

Keywords: Streptococcus mutans, qRT- PCR, Biofilm, Dental caries, Gas chromatography-mass spectrometry, Glucosyltransferases, Dental plaque

\section{Background}

Dental caries is a complex and multifactorial condition which causes demineralization and progressive destruction of the dental enamel [1]. Streptococcus mutans, a member of endogenous oral microflora has long been implicated to play a key role in the pathogenesis of this disease $[2,3]$. $S$. mutans survival depends strictly on a biofilm lifestyle in its natural ecosystem i.e., dental plaque [4]. Dental plaque

\footnotetext{
* Correspondence: asad.k@rediffmail.com

Medical Microbiology and Molecular Biology lab. Interdisciplinary

Biotechnology Unit, Aligarh Muslim University, 202002 Aligarh, India
}

formation is important for its persistence since biofilms does not allow easy penetration of chemotherapeutic agents, permitting to cause resistance against antibiotics, immune factors and host-derived antibacterial agents [5]. The ability of this bacterium to produce (acidogenic) and tolerate (aciduric) acids coupled with its property of synthesizing extracellular glucans allows its effective colonization in the oral cavity leading to the establishment of highly cariogenic dental biofilms [6]. Extracellular glucans which are synthesized from sucrose by glucosyltransferases (GTFs) play a critical role in the adhesive interactions of $S$. mutans and contributes 
to the structural integrity of dental plaque [7]. S. mutans expresses three different GTFs viz., GTF B, GTF C and GTF D. The insoluble and soluble glucan is mostly synthesized by GTF B and GTC C respectively. However, GTF C is known to synthesize a mixture of soluble and insoluble glucans [8]. These virulence properties thus provide a unique microenvironment for unobstructed survival of S. mutans in the oral cavity [9]. Therefore, approaches to inhibit various factors governing the virulence properties of $S$. mutans, could be an alternative to prevent dental caries.

There are numerous anti-plaque agents that are known to reduce dental biofilm formation amongst which fluoride is a well-known cariostatic agent [10]. However, its excessive use results in side effects like fluorosis and hence its use is limited [11]. Moreover, chlorhexidine which is considered as a standard anti-plaque agent have also been reported as genotoxic [12]. Therefore, despite of the presence of a variety of anti- plaque agents, the quest for an effective agent still continues. Therefore, the development of alternative therapeutic agents with anticariogenic properties and minimal side effects is a promising approach.

Chemotherapeutic agents from natural products have proved to be promising source for the development of new drugs throughout human history [13]. Recently, several studies have shown the feasibility of using medicinal plants as a source of chemotherapeutic agents for the prevention of oral diseases [14].

Zingiber officinale (or ginger), is one of the most extensively used herbs in the Indian system of traditional medicine. Many studies have revealed its numerous pharmacological activities, such as, antioxidant, antibacterial, anti-inflammatory, antinociceptive [15], antimutagenic [16] and hepatoprotective [17]. Furthermore, there are several other studies showing the antibacterial effect of $Z$. officinale against a number of micro-organisms including $S$. mutans [18-20]. However, there are hardly any reports evaluating its anticariogenic potential. Hence, in view of the current need of alternative therapeutic approach, we initiated our study to provide an innovative and comprehensive insight of the effect of $Z$. officinale to inhibit various virulence traits of $S$. mutans.

\section{Methods}

\section{Ethics statement}

This research methodology was conducted in accordance with institutional ethical standards. The study on animals was approved by "Interdisciplinary Biotechnology Unit, Institutional Ethical Committee".

\section{Plant material and preparation of extracts}

Dried roots of Zingiber officinale were purchased from the local market of Aligarh and the species was identified and authenticated in Department of Botany, A.M.U., Aligarh,
India. Crude and solvent fractions of the rhizome were prepared as described earlier [3].

\section{Bacterial strain and culture medium}

Bacterial strain used in this study was S. mutans UA159, which was grown in Brain Heart Infusion (BHI) Broth (Himedia Labs, Mumbai, India) at $37^{\circ} \mathrm{C}$ in a $5 \% \mathrm{CO}_{2}$ anaerobic atmosphere. It was sub cultured regularly and stored at $-80^{\circ} \mathrm{C}$ as glycerol stock.

\section{Determination of bacteriostatic (MIC) and bactericidal (MBC) concentration}

The MIC and MBC of the crude (CR) extract and methanolic (ME) fraction against $S$. mutans was determined by microdilution method [21]. For the determination of MIC, twofold serial dilution of the compound was performed. The inoculum was prepared in BHI, and density was adjusted to $0.5 \mathrm{Mcfarland}$ standards $\left(10^{8} \mathrm{CFU} \mathrm{ml}{ }^{-1}\right)$ and diluted to 1: 100 for the broth microdilution procedure. Microtitre plates were incubated at $37^{\circ} \mathrm{C}$, and the MIC was recorded after $24 \mathrm{~h}$. The concentrations ranged from 2.44 to $5000 \mu \mathrm{g} \mathrm{ml}^{-1}$ in a series of twofold dilutions. The MIC was determined as the lowest concentration that totally inhibits visible bacterial growth while $M B C$ was determined by subculturing the test dilutions on a mitis salivarius (MS) agar plates and incubated further for $24 \mathrm{~h}$. The highest dilution that yielded no bacterial growth on solid medium was taken as MBC. All these determinations represent the mean of three independent experiments.

\section{Gas chromatography-mass spectrometry (GC-MS) analyses} of crude extract and methanolic fraction of $Z$. officinale

Constituents of $C R$ extract and ME fraction were analyzed by GCMS- $\mathrm{QP}_{2010}$ plus using the protocol described elsewhere [3]. The major constituents of the crude and ethanolic fractions were identified by drawing a comparison between the GC retention times with MS reference database of NIST05s.LiB.

\section{Kinetic killing assay}

The kinetics of the bacterial-killing effect of CR extract and ME fraction of $Z$. officinale was assessed against $S$. mutans by using modified method of Koo et al. [22]. Tubes containing S. mutans suspension $\left(5 \times 10^{7}\right.$ $\mathrm{CFU} \mathrm{ml} \mathrm{m}^{-1}$ ) and different sub- MIC levels of crude extract and methanolic fraction $\left(8,16,32,64\right.$ and $128 \mu \mathrm{g} \mathrm{ml}^{-1}$, final concentration) were incubated. Samples were removed for colony counting at different time interval over $24 \mathrm{~h}$. These samples were serially diluted with PBS and aliquots of $5 \mu \mathrm{L}$ were incubated into BHI agar. The plates were then incubated, and CFUs were counted. A bactericidal effect was defined as a $>3-\log \mathrm{CFU} \mathrm{m} \mathrm{m}^{-1}$ decrease from the original inoculum. 


\section{Sucrose-dependent and sucrose-independent adherence assay}

Adherence to glass surface assay was performed by the method of Hamada et al. with slight modifications [23]. Briefly, the bacteria were grown at $37^{\circ} \mathrm{C}$ at an angle of $30^{\circ}$ for $24 \mathrm{~h}$ in a glass tube containing $10 \mathrm{ml}$ of BHI with or without $5 \%(\mathrm{w} / \mathrm{v})$ sucrose and sub-MIC concentrations of the extracts (CR and ME). The solvent controls included $\mathrm{BHI}$ with (sucrose dependent) and without sucrose (sucrose independent) and equivalent amounts of DMSO and ethanol. After incubation, the planktonic cells were decanted gently from the glass tubes. The adhered cells were then removed by adding $0.5 \mathrm{M}$ of $\mathrm{NaOH}$ followed by vortexing. The cells were washed and suspended in saline. The adherence was quantified spectrophotometrically at $600 \mathrm{~nm}$. All these determinations were performed in triplicates, using untreated BHI medium as control.

$$
\begin{aligned}
\text { Percentage adherence }= & \text { (O.D. of adhered cells } / \\
& \text { O.D. of total cells }) \times 100 .
\end{aligned}
$$

\section{Biofilm formation assay}

The inhibitory effect of CR extract and ME fraction of $Z$. officinale on biofilm formation by $S$. mutans was performed using the protocol described elsewhere [24]. Briefly, $50 \mu \mathrm{L}$ of overnight culture of $S$. mutans $\left(10^{5}-10^{6} \mathrm{CFU} \mathrm{ml} \mathrm{m}^{-1}\right)$ was inoculated into $150 \mu \mathrm{L}$ of BHI with $5 \%$ (w/v) sucrose containing various concentrations of $\mathrm{CR}$ extract and $\mathrm{ME}$ fraction with respective controls. After incubation at $37^{\circ} \mathrm{C}$ for $24 \mathrm{~h}$, media and unbound cells were decanted from the microtitre plates. The remaining planktonic cells were removed by gently rinsing with sterile water. The wells with attached cells (biofilms) were fixed with formalin (37\%, diluted $1: 10$ ) plus $2 \%$ sodium acetate. Each well was stained with $200 \mu \mathrm{L}$ of $0.1 \%$ Crystal Violet for $15 \mathrm{~min}$ at room temperature. After two rinses with sterile water, bound dye was removed from the cells with $100 \mu \mathrm{L}$ of $95 \%$ alcohol. Plates were then set on a shaker for $10 \mathrm{~min}$ to allow full release of the dye. Biofilm formation was then quantified by measuring optical density of the suspension at $600 \mathrm{~nm}$ by a microplate reader (BIORAD iMark TM Microplate reader, India). Separate biofilms were formed in the presence extracts for time-dependent effect at 6,12 , 20 and $24 \mathrm{~h}$.

Inhibition of water-insoluble and soluble glucan synthesis To examine the inhibitory effect on water insoluble and soluble glucan production by $S$. mutans, sub-MIC concentration $\mathrm{CR}$ extract and ME fraction of $Z$. officinale was added to the inoculum in BHI containing 5\% sucrose and incubated at $37^{\circ} \mathrm{C}$. Crude GTFs were prepared from the culture supernatants of $S$. mutans by previously described method [25]. A reaction mixture consisting of $0.25 \mathrm{ml}$ of crude enzyme and varying concentrations of the extracts (CR extract and ME fraction) in $20 \mathrm{mM}$ phosphate buffer ( $\mathrm{pH} 6.8$ ) containing $0.25 \mathrm{ml}$ of $0.4 \mathrm{M}$ sucrose was incubated at $37^{\circ} \mathrm{C}$ for $18 \mathrm{~h}$. The tube was removed post incubation and the contents were washed with distilled water. Total amounts of water-soluble and insoluble glucan were measured by the phenol-sulphuric acid method [26]. Three replicates were made for each concentration of the extracts and ethanol was used as control.

\section{Effect on cell-surface hydrophobicity of S. mutans}

The cell surface hydrophobicity of $S$. mutans was measured according to Microbial adhesion test to hydrocarbon [27]. Briefly, cells grown in BHI medium supplemented with different sub- MIC concentrations of the extracts. These cells were washed thrice and suspended in $0.85 \%$ sterile saline so that their optical density was adjusted to 0.3 at $600 \mathrm{~nm}$. The cell suspension $(3.0 \mathrm{ml})$ was placed in tubes and $0.25 \mathrm{ml}$ of toluene was added. The tubes were agitated uniformly in a vortex mixer for 2-3 min and allowed to equilibrate at room temperature for $10 \mathrm{~min}$. After toluene phase separation from the aqueous phase, the O.D. of the aqueous phase was determined spectrophotometrically at $600 \mathrm{~nm}$. S. mutans with a hydrophobic index $>70 \%$ was arbitrarily classified as hydrophobic.

\section{Effect on glycolytic pH drop}

The level of the glycolytic $\mathrm{pH}$ drop of $S$. mutans was measured, as described elsewhere [28]. Briefly, S. mutans cells from the suspension cultures were harvested and washed once with salt solution containing $50 \mathrm{mM} \mathrm{KCl}$ and $1 \mathrm{mM} \mathrm{MgCl} 2$. They were suspended in a salt solution containing sub- MIC concentration $\left(128 \mu \mathrm{g} \mathrm{ml}^{-1}\right)$ of the extracts (CR extract and ME fraction) or the vehicle control. The $\mathrm{pH}$ was adjusted between 7.2-7.4 with $0.2 \mathrm{M}$ $\mathrm{KOH}$ solution. Sufficient glucose was added to obtain a concentration of $1 \%(\mathrm{w} / \mathrm{v})$ and the decrease in $\mathrm{pH}$ was assessed over a period of 60 min using a glass electrode. The initial rate of $\mathrm{pH}$ drop, was calculated using the $\mathrm{pH}$ values in the linear portion (0-10 min) which can give the best measure of the acid production capacity of the cells.

\section{Cell permeabilization and F- ATPase activity}

Permeabilization of $S$. mutans cells was done by subjecting the cells to $10 \%$ toluene $(\mathrm{v} / \mathrm{v})$ followed by two cycles of freezing and thawing as described elsewhere [25]. FATPase was measured in terms of the release of phosphate. The standard reaction mixture consisted: $75 \mathrm{mmol}$ of Tris-maleate buffer ( $\mathrm{pH} 7.0$ ) containing 5 mM ATP, 10 mmol of $\mathrm{MgCl}_{2}$, permeabilized cells and different concentrations of the crude extract and the methanolic fraction $\left(8-128 \mu \mathrm{g} \mathrm{ml}^{-1}\right)$. The released phosphate was determined over $10 \mathrm{~min}$ of reaction time by the method of Bencini et al. [29]. 


\section{Effect on Surface Protein Ag I/ II}

The total protein from $S$. mutans cells was conjugated to rabbit anti-Ag I/II to equate and calculate the levels of Ag I/II protein (or SpaP). The amount of protein Ag I/II from control and treated samples was calculated. $10 \mu \mathrm{g}$ of total protein from the treated and untreated samples was dissolved in $100 \mu \mathrm{l}$ of $20 \mathrm{mM}$ carbonate buffer ( $\mathrm{pH}$ 9.3) and was coated on the polystyrene plates. The plates were washed with PBS-Tween and was blocked with 5\% skimmed milk in bicarbonate buffer. The plates were washed again with PBS-T thrice and then incubated with rabbit polyclonal $\mathrm{Ag} \mathrm{I} / \mathrm{II}$ antibody at $37^{\circ} \mathrm{C}$ for $2 \mathrm{~h}$. The plates were rewashed thrice with PBS and the incubated for $2 \mathrm{~h}$ with $100 \mu \mathrm{l}$ of anti-rabbit peroxidase coated antibody, dilutions ranging from 1:100 to 1:1000000. The plates were washed again with PBS and the $50 \mu \mathrm{l}$ of TMB $\left(3,3^{\prime}, 5,5^{\prime}\right.$ tetramethylbenzidine). The reaction was stopped immediately after the color appeared using $50 \mu \mathrm{l}$ of $4 \mathrm{~N} \mathrm{H}_{2} \mathrm{SO}_{4}$ [3]. Quantification of the intensity was done by measuring optical density (OD) at $450 \mathrm{~nm}$ by a microplate reader (BIORAD iMark TM Microplate reader, India).

\section{Target preparation and docking analyses}

The crystal structure of C-terminal region of Surface Protein Antigen (SpaP or Ag I/ II) of S. mutans was downloaded from protein databank having PDB ID: 3QE5 whereas, the structure of BrpA (Biofilm Regulatory Protein) was modelled using Modeller 9v7 [30]. The target preparation for docking was done by removing all waters molecules from the structure and by adding hydrogen atom to the target protein (SpaP or BrpA). Program Q-Site Finder was used for the detection of active site of the protein [31] (Laurie and Jackson 2005). Two dimensional structures of selected compounds were downloaded from Pubchem database. GOLD 5.0 version was used to study the binding orientation of selected compounds into the S. mutans SpaP and BrpA structure [32]. The default parameters of the automatic settings were used to set the genetic algorithm parameters. The best protein-ligands complexes were selected based on the scoring function of GOLD fitness score.

\section{Confocal microscopy}

To analyse the effect of the CR extract and ME fraction on $S$. mutans biofilm, cells were grown on glass coverslips. Sample preparation was done using the protocol described elsewhere [3]. Fluorescence emission was observed using confocal scanning laser microscope (Fluoview FV200). The images of control and treated samples were averaged and compared.

\section{Scanning electron microscopy}

The effect of the plant extracts (CR and ME) on structural integrity of biofilm was also observed by scanning electron microscopy (SEM). The samples were prepared for SEM examination as described elsewhere [25]. Also, the aseptically removed jaws of the animals (wistar rats) were stored in normal saline and were directly visualized under SEM. The experiment was run in triplicates. Samples were analysed by SEM (Hitachi S-3000 N; High Technology Operation, Japan) at several magnifications.

\section{RNA isolation and real-time quantitative PCR (qRT-PCR)}

To analyse the effect of plant extracts (CR and ME) on expression of virulence genes of S. mutans, the organism was cultured in BHI medium supplemented with sub MIC concentration of the extracts. Bacterial culture $\left(\mathrm{OD}_{600}=0.8\right)$ were diluted at a ratio of 1:50 followed by their inoculation into BHI media and were incubated at $37^{\circ} \mathrm{C}$ for an overnight growth. RNA was isolated and purified and qRT- PCR was performed using the protocol described elsewhere [25]. The primer sequences are provided in Additional file 1.

\section{In vivo toxicity studies of $\mathrm{CR}$ fraction and ME fraction}

Acute oral toxicity of plant extracts was evaluated in accordance to Organization for Economic and Cooperation Development (OECD) guidelines (2001) for testing plant extracts. A limit test $\left(5000 \mathrm{mg} \mathrm{kg}^{-1}\right.$ body weight of animal) was carried out using five male wistar rats ranging from $80-120 \mathrm{~g}$ in weight, in all the groups used. All animals were observed for change in weight, behavioural changes and mortality till $14^{\text {th }}$ day post administration of dose.

\section{Caries induction in rats}

To determine the effects of the CR extract and ME fraction on oral colonization and cariogenic potential of $S$. mutans, a total of 30 rats were purchased. These animals were divided three groups; a control and two test groups ( $\mathrm{n}=10$ per group). All the animals were fed with erythromycin water $\left(100 \mu \mathrm{g} \mathrm{ml}^{-1}\right)$ and a regular diet for 3 days in order to lower the microbial load. To confirm the absence of $S$. mutans colonization in the oral cavity, oral swab was plated on MSB plates. The animals were offered $5 \%$ sucrose diet ad libitum throughout the experiment in order to enhance the infection by S. mutans. On $4^{\text {th }}$ day, the animals were inoculated with $1.4 \times 10^{10} \mathrm{CFU}$ of streptomycin resistant strain of S. mutans (MT8148R), onto the animals' molars surfaces once every day for five consecutive days to allow oral colonization. The treatment was given twice daily, by applying the plant extracts topically on the teeth of animals by means of a camel's hair brush. Swab samples were then taken from the surfaces of animal molars on the first day and at the first, third, sixth, eighth and tenth week's post-inoculation. The samples from control and treated groups were pooled in $2 \mathrm{ml} 10$ $\mathrm{mM}$ potassium phosphate buffer, serially diluted and plated on MSB agar plates containing streptomycin for 
total cell counts. The plates were incubated at $37^{\circ} \mathrm{C}$ for 2 days before enumeration of colonies of $S$. mutans. The percentages of the $S$. mutans cells were calculated to determine its oral colonization in the animals. At the end of the experimental period, all the animals were sacrificed. The jaws were then aseptically dissected and sonicated in $5 \mathrm{ml}$ of $154 \mathrm{mM}$ sterile $\mathrm{NaCl}$ in order to dislodge the dental plaque. These samples of plaque were serially diluted and were streaked on mitis salivarius agar plates to estimate the S. mutans population. These plates were incubated at $37^{\circ} \mathrm{C}$ for 2 days before enumeration of colonies. All of the jaws were defleshed, and suspended in 3.7\% formaldehyde until caries scoring. All molars of the animals were examined under a dissecting microscope and carious lesions were scored by a Larson's modification of Keyes system [33].

The results obtained were analysed by Student's t test, with $\mathrm{p}<0.05$ considered as statistically significant.

\section{Statistical analysis}

The data are presented as mean \pm standard deviation. The intergroup differences were estimated by one-way analysis of variance (ANOVA), followed by a post hoc multiple comparison (Tukey's test) to compare the multiple means. Values were considered statistically significant when $p$ value was $<0.05$. The statistical analyses were performed using SPSS 12 software.

\section{Results}

Minimum inhibitory concentration (MIC) and minimum bactericidal concentration $(\mathrm{MBC})$

The MIC and MBC of the both the plant extracts (CR and $\mathrm{ME}$ ) of $Z$. officinale against $S$. mutans was found to be $256 \mu \mathrm{g} \mathrm{ml}^{-1}$ each.

\section{Phytochemical analysis of the extracts by GC- MS}

The phytochemical composition of $\mathrm{CR}$ extract and $\mathrm{ME}$ fraction of $Z$. officinale determined by GC-MS are listed in detail in Additional file 2. Some of the secondary metabolites like D-nerolidol, a Curcumen, Tran- 10 - Shogaol, Paradol etc. were found to be common in both the extracts.

\section{Kinetic killing assay}

The kinetics of the antimicrobial effect of CR extract and ME fraction against S. mutans is demonstrated in Figure 1. Both these extracts killed $S$. mutans in a time as well as dose dependent manner. CR extract at $128 \mathrm{\mu g} \mathrm{ml}^{-1}(0.5$ MIC) showed an antibacterial activity against $S$. mutans, with more than $5-\log \mathrm{CFU} \mathrm{ml}{ }^{-1}$ decrease after $24 \mathrm{~h}$ of incubation, whereas $\mathrm{ME}$ fraction at the same concentration showed a reduction of 4- $\log \mathrm{CFU} \mathrm{ml} \mathrm{m}^{-1}$.

\section{Inhibitory effect on bacterial adherence}

The effect on sucrose dependent (SD) and sucrose independent (SI) adherence of S. mutans treated with different
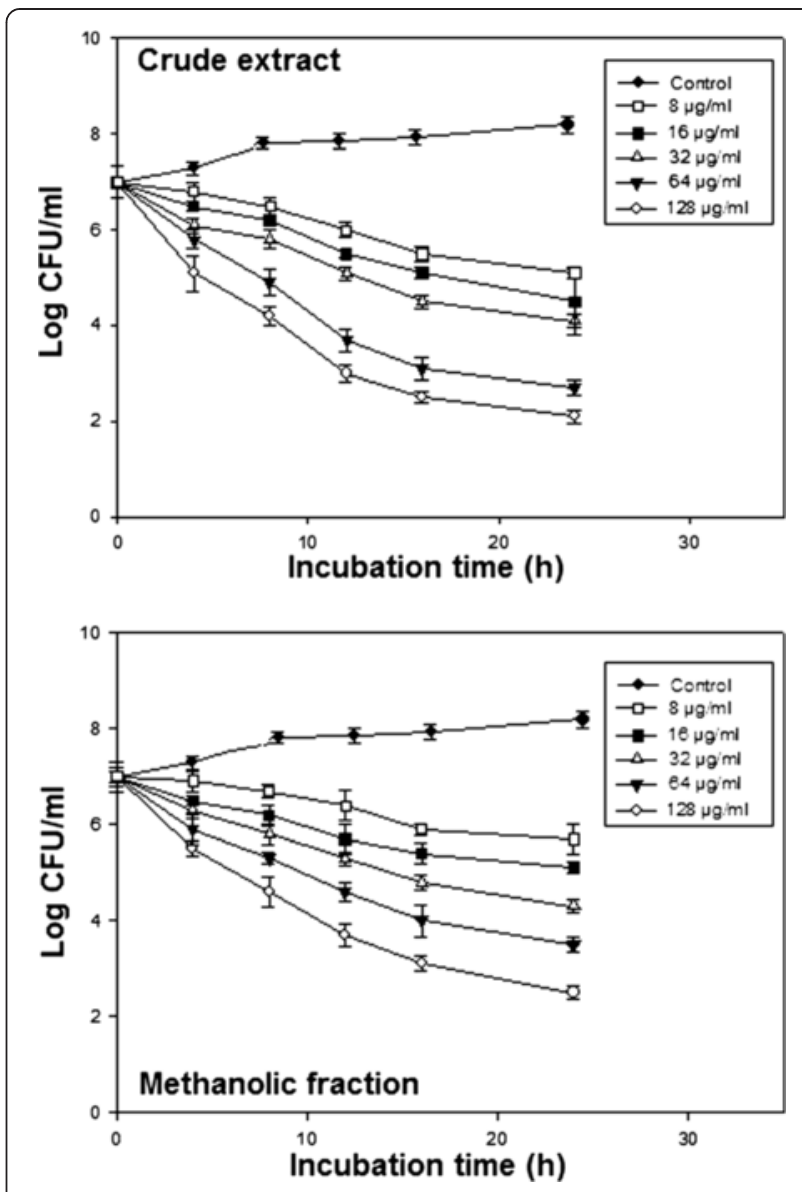

Figure 1 Kinetic killing curve. The bacteriostatic activity of $C R$ extract and ME fraction at different sub- MIC levels on S. mutans cell cultures over $24 \mathrm{~h}$ of incubation.

concentrations of the CR extract and ME fraction is given in Figure 2 ( $\mathrm{a}$ and $\mathrm{b})$. Both of them displayed a strong anti-adherence activity by inhibiting the SD as well as SI adherence. However, the inhibition in SD adherence was slightly pronounced compared to SI adherence. CR extract at $128 \mu \mathrm{g} \mathrm{ml}^{-1}$ was found to reduce SD and SI adherence by $78 \%$ and $73 \%$ respectively, whereas ME fraction at the same concentration reduced the same by $72 \%$ and $70 \%$ respectively.

\section{Inhibition of glucosyltransferases activity}

The effect of different concentrations of CR extract and ME fraction was assessed against GTF activity in terms of the synthesis of water soluble glucan (WSG) and water insoluble glucan (WIG). The inhibition of glucan synthesis was found to be concentration dependent in the reaction. However, the reduction was observed to be more significant in case of water-insoluble glucan. At sub- MIC level $\left(128 \mu \mathrm{g} \mathrm{ml}^{-1}\right)$, the CR extract reduced the formation of WSG and WIG to approximately $>70 \%$ as shown in 


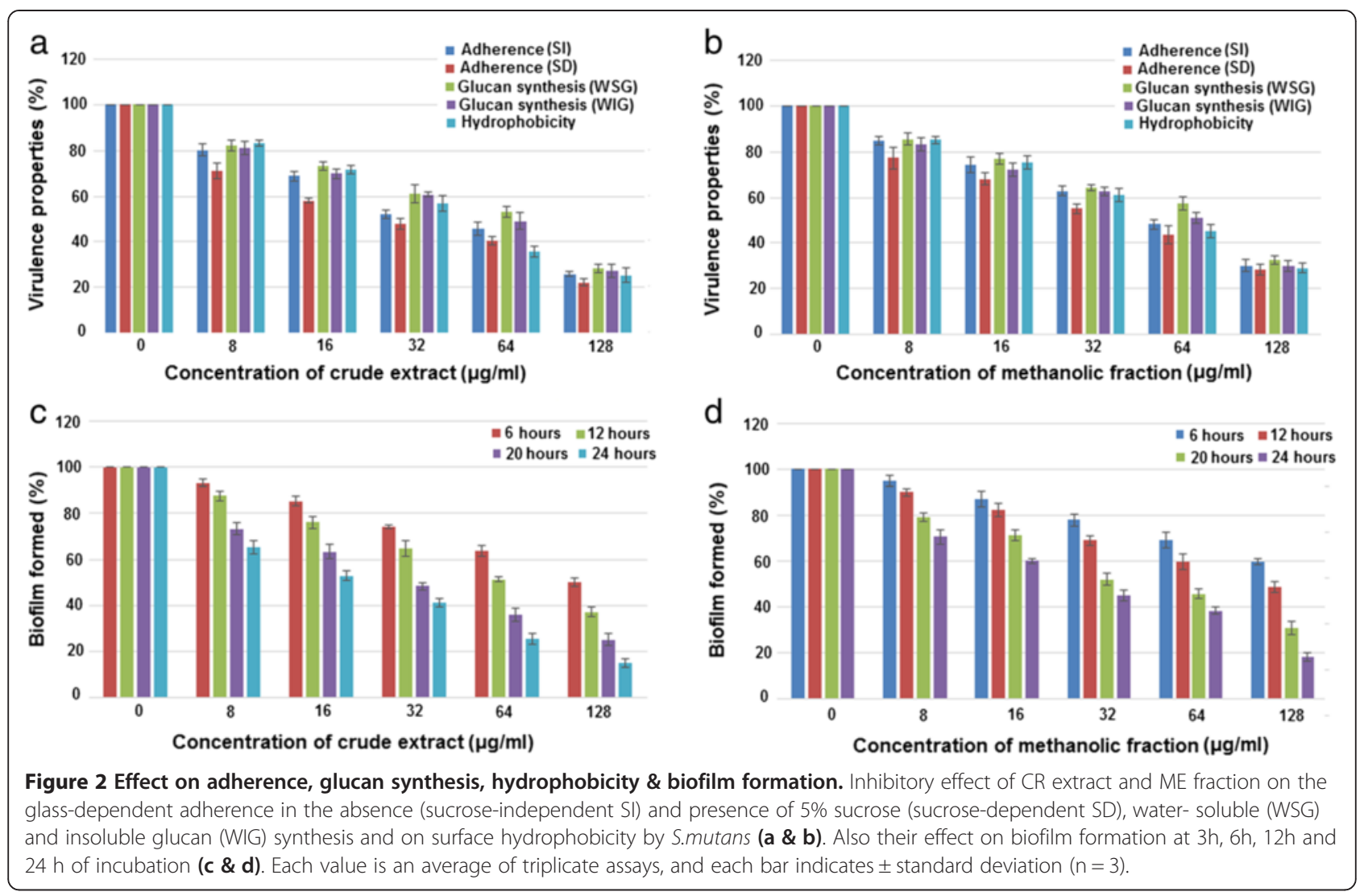

Figure 2 ( $\mathrm{a} \& \mathrm{~b})$. However, ME fraction was found to reduce the same by approximately $70 \%$.

Effect on cell-surface hydrophobicity index of S. mutans The hydrophobicity index (HPBI) was significantly reduced in a dose dependent manner when compared with control. As shown, at sub-MIC concentration $\left(128 \mu \mathrm{g} \mathrm{ml}^{-1}\right)$, the CR extract and ME fraction reduced the HPBI by $75 \%$ and $71 \%$ respectively (Figure $2 \mathrm{a} \& 2 \mathrm{~b}$ ).

\section{Biofilm formation by $S$. mutans}

The CR extract and ME fraction inhibited biofilm formation in a concentration dependent manner. The effect was tested at $6,12,20$ and $24 \mathrm{~h}$ to evaluate whether it could affect $S$. mutans in each phase of biofilm growth. The results demonstrated that the effect of both the extracts was concentration-dependent as well as dependent on biofilm growth phases as shown in Figure 2 (c \& d). The percentage of adherent cells under various concentrations of extracts was found to decline with every successive growth phase. At $6 \mathrm{~h}$ of biofilm growth, CR extract and $\mathrm{ME}$ fraction at $128 \mu \mathrm{g} \mathrm{ml} \mathrm{m}^{-1}$ reduced biofilm formation by $50 \%$ and $40 \%$ respectively. At 12 h, 50\% reduction was observed by $\mathrm{CR}$ extract and ME fraction at a concentration of $64 \mu \mathrm{g} \mathrm{ml}^{-1}$ and $128 \mu \mathrm{g} \mathrm{ml}^{-1}$ respectively. However, at $20 \mathrm{~h}$ and $24 \mathrm{~h}$, the percentage of adherent cells were reduced to $>70 \%$ and $>80 \%$ at maximum concentration as compared to control group. Precisely, biofilm formation was inhibited mostly during the active accumulated phase, initial plateau accumulated phase and plateau accumulated phase of growth.

\section{Glycolytic pH drop}

As shown in Figure 3a, the glycolytic acid production of $S$. mutans was significantly inhibited by CR extract and ME fraction at a concentration of $128 \mu \mathrm{g} \mathrm{ml}^{-1}$ (0.5 MIC). In control, the onset pH 7.25 was decreased to 4.11 after $60 \mathrm{~min}$ of incubation. Whereas, after treatment with ME fraction and CR extract this acidic $\mathrm{pH}$ (4.11) was raised to 5.85 and 6.32 respectively. Above all, the $\mathrm{pH}$ drop recorded in first $10 \mathrm{~min}$ of incubation (known as initial $\mathrm{pH}$ drop) was observed maximum in case of control with $\mathrm{pH}$ values of 7.25 to 5.41 . However, CR extract showed minimum pH drop with values 7.25 to 6.83 . (Tukey test, $\mathrm{p}<0.05$ ).

\section{F- ATPase activity}

The result of F-ATPase activity assay is shown in Figure 3b. It was found that the F-ATPase activity of $S$. mutans cells was inhibited dose-dependently. At $64 \mu \mathrm{g} \mathrm{ml}{ }^{-1}$ (0.25 MIC), ME fraction and CR extract declined the F- ATPase activity by $44 \%$ and $53 \%$ respectively. However, at $128 \mu \mathrm{g} \mathrm{ml}^{-1}(0.5$ 


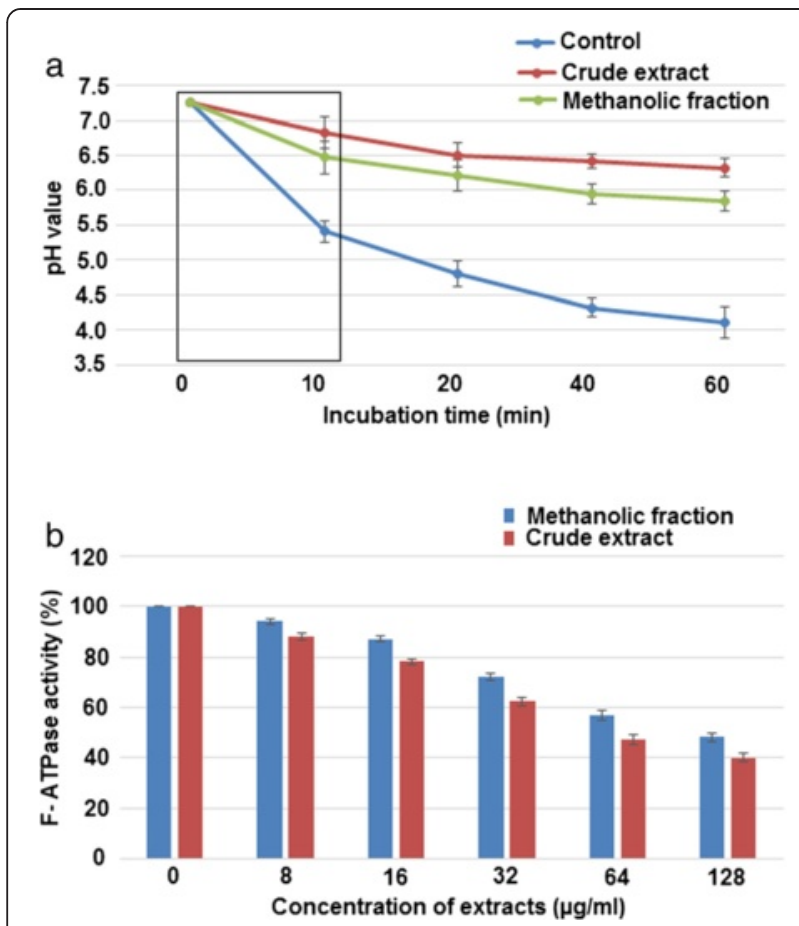

Figure 3 Inhibitory effect on acid production and adaptation. Effect of sub-MIC concentration $\left(128 \mathrm{\mu g} \mathrm{ml}^{-1}\right)$ of CR extract and ME fraction on (a) glycolytic pH-drop (the values enclosed in box corresponds to the initial rate of the $\mathrm{pH}$ drop) (b) F- ATPase activity.

$\mathrm{MIC}$ ), the activity was reduced to $52 \%$ and $60 \%$ respectively as compared to the control $(\mathrm{p}<0.05)$.

\section{Inhibitory effect on surface protein antigen, SpaP}

As shown in Figure 4, the reduction of surface protein antigen (spaP or Ag I/II) in samples treated with $\mathrm{ME}$ fraction and CR extract was found to reduce by approx. $50 \%$ (OD 0.73 ) and 70\% (OD 0.46 ) respectively at 1:100 antibody dilution as compared to the control (OD 1.45).

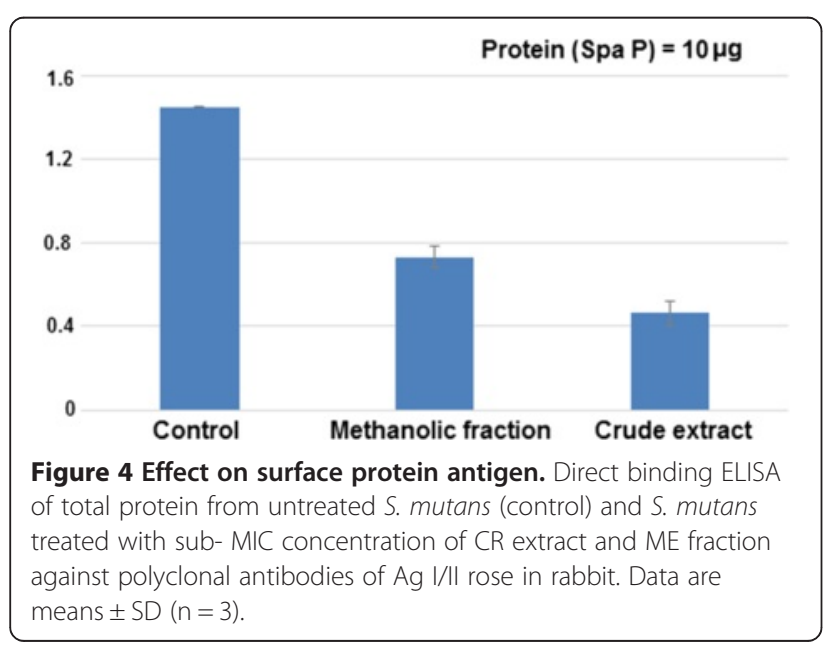

Docking studies on spaP and brpA with different compounds of CR extract and ME fraction

All the ligands depicted by GC- MS were docked into the active sites of proteins SpaP and BrpA. Of all these ligands, seven ligands from crude extract (Gingerol, Methyl linoleate, Shogaol, Citronellal, Octadecanoic acid, Capsaicin and Beta- farnesene) and six from methanolic fraction (Methyl linoleate, Zingiberene, citronellal, Elaidic acid, Palmitate and Shogaol) were identified as the best compounds depending on their gold score as shown in Figure 5. Compounds from crude extract (Figure 5a \& 5b) were found to dock in the active site of target proteins SpaP and BrpA with a range of 60-76 and 63-76 of Gold fitness score respectively. Whereas, compounds from methanolic fraction (Figure 5c \& 5d) were found to interact with a range of 60-71 Gold fitness score for both the proteins. Furthermore, in case of crude extract, thirteen amino acids (Glu1215, Glu1216, Gly1261, Arg1263, Pro1264, Lys1265, Ala1267, Ser1308, Tyr1309, Gln1312, Tyr1314, Ile1326 and Ile1328) were found to be common for all the compounds in stabilizing the complex of SpaP protein as shown in Figure $5 \mathrm{a}$ and twenty three amino acids (Leu15, Met16, Gly17, Val18, Ile37, Val39, Thr48, Met50, Ile106, Met108, Gly110, Leu111, Leu114, Val115, Val118, Gln177, Ser182, Val184, Leu185, Ile188, Leu201, Val204 and Leu229) were found to be common for all the compounds in stabilizing the complex of BrpA protein as shown in Figure 5b. Whereas, in case of methanolic fraction, eleven amino acids (Gly1173, Glu1215, Glu1216, Pro1264, Lys1265, Ser1308, Tyr1309, Gln1312, Tyr1314, Ileu1326 and Asn1330) were found to be common for all the compounds in stabilizing the complex of SpaP protein as shown in Figure $5 \mathrm{c}$ and twenty three amino acids (Leu15, Gln17, Val18, Asp34, Ser35, Ile37, Val39, Ile106, Asn107, Met108, Gly110, Leu111, Leu114, Val115, Ser160, Arg161, Arg173, Arg178, Val180, Ser182, Ileu188, Leu229 and Ile232) were found to be common for all the compounds in stabilizing the complex of BrpA protein as shown in Figure 5d.

\section{Impairment of biofilm formation visualized by scanning and confocal electron microscopy}

SEM depicted the impact of CR extract and ME fraction on the activity of $S$. mutans to synthesize glucans and on the structural integrity of biofilm formed (Figure 6A). In concordance with the aforesaid results the treated group displayed significant dispersion of cells suggesting reduced amount of glucan synthesis that would have otherwise resulted in adherence. On the contrary, the control sample as shown in Figure 6A (a) showed apparent clumping of cells with chain formation embedded into the exopolysaccharide pool.

However, the distortion of biofilm architecture of $S$. mutans was also analysed by confocal laser scanning 

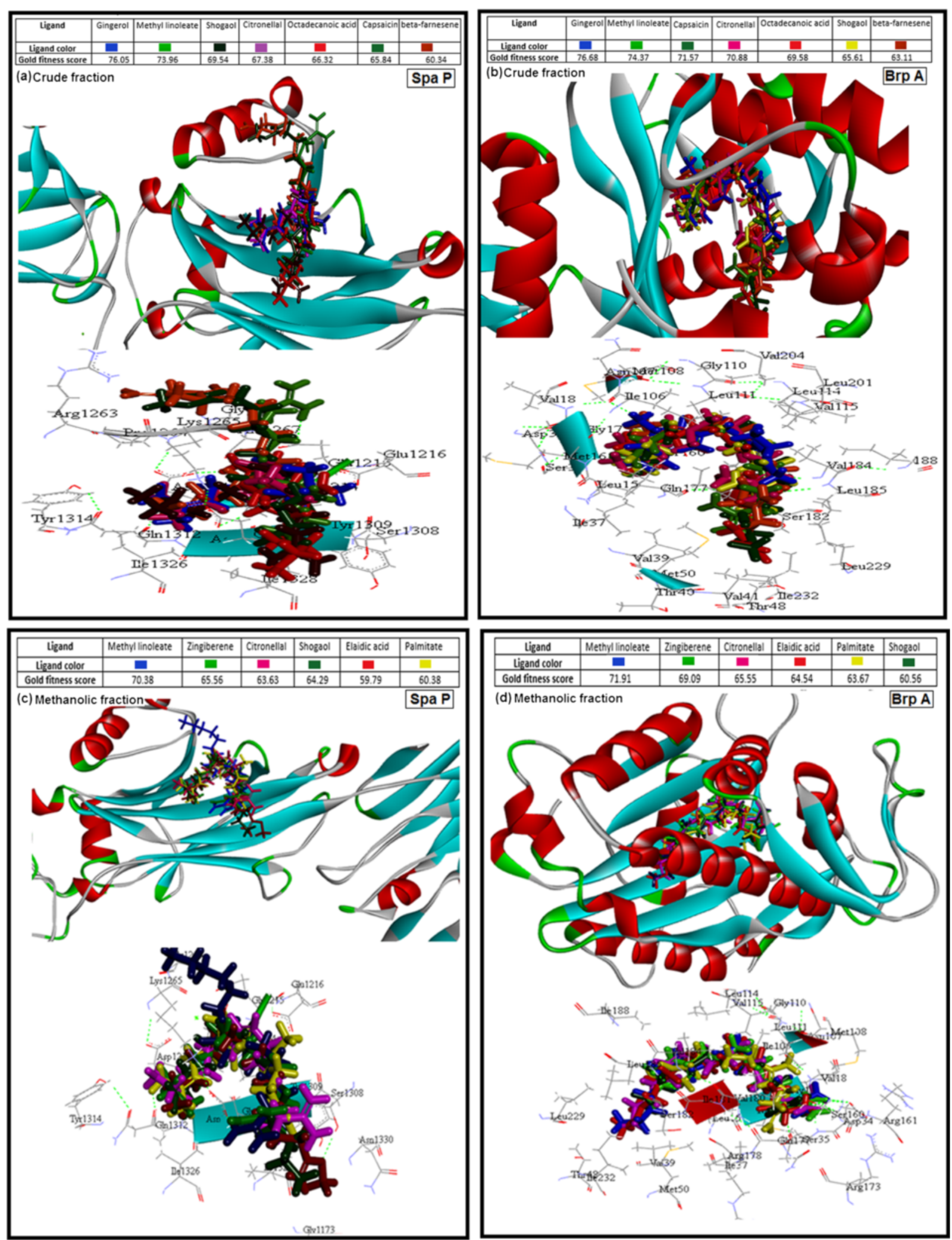

Figure 5 Docking analysis. Binding pattern of the compounds from crude extract (a \& b) and methanolic fraction (c \& d) analysed by GC-MS showing best docking score within the active sites of Spa and Brp A. 


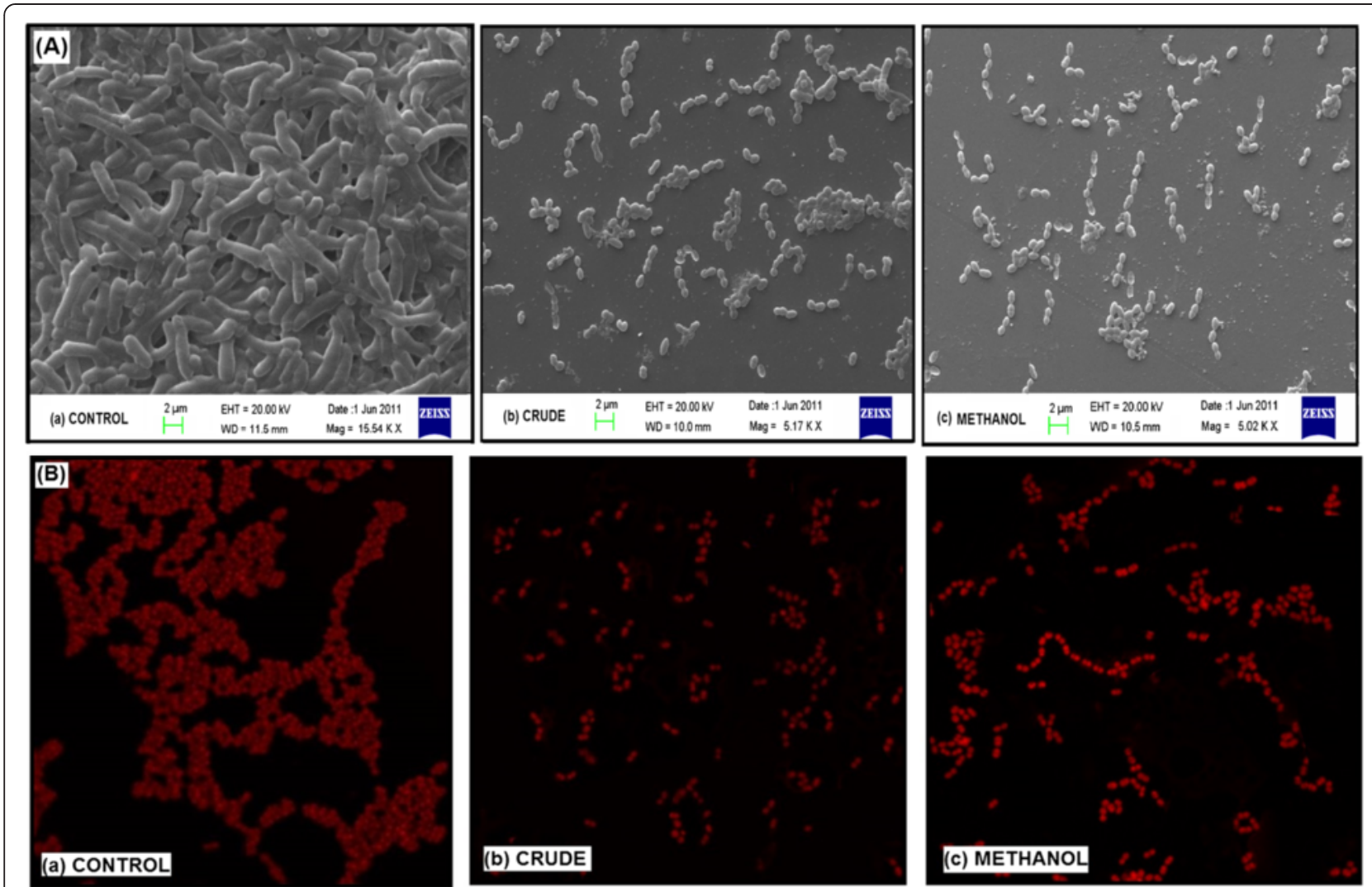

Figure 6 Electron microscopy. SEM (A) and CLSM images (B) of S. mutans biofilm formed in the presence and absence of the sub- MIC levels of extracts after $24 \mathrm{~h}$ of incubation.

microscopy (CLSM). As shown in Figure 6B, in the absence of treatment (a), the cells were aggregated with an evident chain forming pattern. However, unlike control, the groups treated showed apparent scattering of cells without any cluster or chain formation, suggesting reduced interaction between cells, resulting in impaired biofilm formation. However, the cells treated with CR extract were more dispersed as compared to the ones treated with ME fraction.

\section{Gene expression profile}

The expression profile of different virulence genes ( relA, $g t f C, \operatorname{brp} A$ and $\operatorname{comDE}$ ) of $S$. mutans treated crude extract and methanolic fraction was determined (Figure 7). The entire set of virulence genes was found to be down regulated after treatment. Crude extract repressed the expression level of relA, gtfC, brpA and comDE by $60 \%, 74.6 \%$, $85 \%$ and $68.6 \%$ respectively as compared to the control. Likewise, methanolic fraction suppressed the expression level of relA, gtfC, brpA and comDE by $48.5 \%, 59 \%, 68 \%$ and 54\% 54\% respectively. Evidently, both crude extract and methanolic fraction suppressed $\operatorname{brp} A$ gene to the maximum ( $85 \%$ and $68 \%$ respectively) followed by the suppression of $g t f C$ gene.

\section{Caries reduction in vivo}

After toxicity assays were performed, the animals did not display any behavioural or weight changes, neither any mortality occurred post oral toxicity assay indicating that CR extracts and ME fraction were absolutely nontoxic. The weekly recovery of $S$. mutans cells over 5 weeks post treatment is shown in Additional file 3. It was found that there was significant reduction in the recovery of $S$. mutans from rats treated with CR extract and ME fraction. However, CR extract showed slightly better activity than ME fraction. Furthermore, Figure 8 shows the reduction in smooth as well as sulcal surface caries after treatment. The overall reduction in smooth surface caries was more pronounced as compared to the sulcal surface caries post treatment. CR extract consistently showed better anticariogenic activity by reducing severity of smooth surface caries to $80 \%$ (slight), $83 \%$ (moderate) and $86 \%$ (extensive) as compared to ME fraction which reduced the caries by $40 \%$ (slight), 52\% (moderate) and 66\% (extensive).

\section{Scanning electron micrograph and radiographs of untreated and treated rats teeth}

The SEM analysis of the rats' teeth clearly depicted the demineralization of the dental margins in untreated 


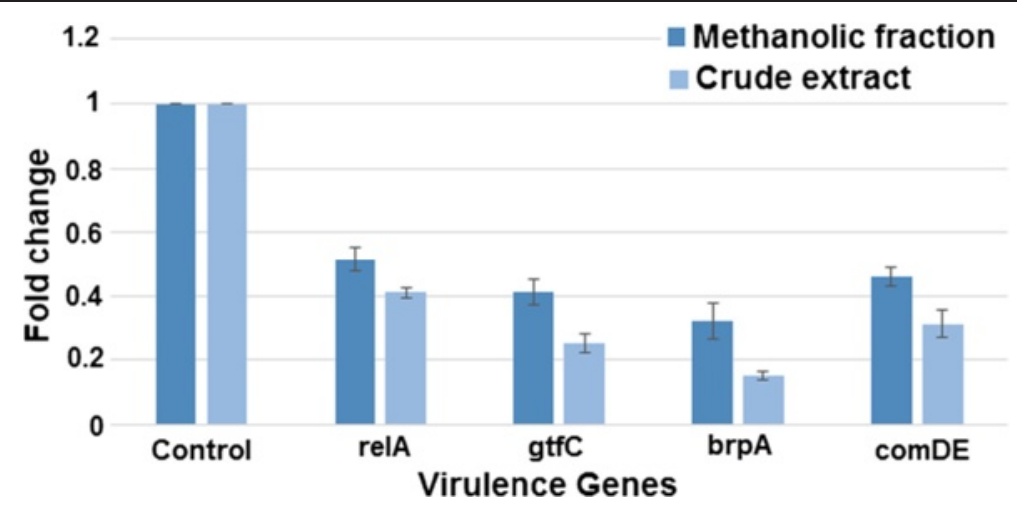

Figure 7 Relative quantification of selected virulent genes expression by quantitative RT-PCR. Expression profile by real time PCR of various virulence genes of $S$. mutans in response to the treatment with sub- MIC levels of extracts. Each value is an average of triplicate assays. Data are means \pm SD $(n=3)$.

group (Figure 9a), while the groups treated with crude extract and methanolic fraction showed smooth dental margins as shown in Figure 9b' and 9b' respectively. Furthermore, the panels in Figure 9 c, c' c" shows the dental surface. It was clearly observed that in untreated samples (Figure 9c), the surface has an evident biofilm embedded in exopolysaccharide pool whereas in treated groups (Figure 9c' \& 9c"), the dental surface was clear from any such exopolysaccharide projections as visible in control.

Figure 10 shows the digital radiographs of untreated (a \& b) and treated rat teeth with CR extract (c \& d) and ME fraction (e \& f). As shown in Figure 10a, there

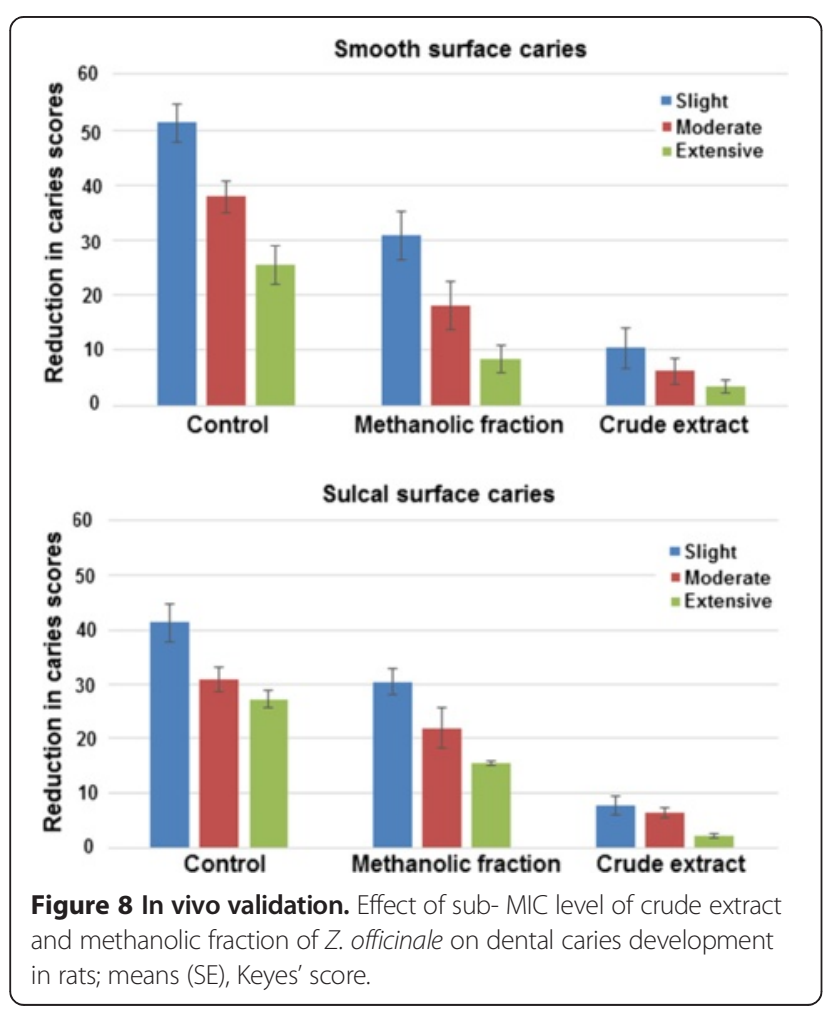

was an evident black space (as spot) that corresponded to a carious lesion whereas, $10 \mathrm{~b}$ was the flipped side of the jaw showing the caries lesion reaching to the pulp cavity revealed by a V- lining surrounding the bottom of the tooth. This concavity reaching to the pulp of the tooth corresponded to an inflamed and infective condition known as pulpitis. However, in 10c and 10e, there was no such space or spot seen that confirmed the absence of caries. Furthermore, 9d and 9f show normal radiograph without any sign of pulpitis which could have been sequelae of dental caries. The line extending downwards are the roots of the teeth and should not be confused with inflammation of the pulp, as they are not surrounding the root of the tooth in a V-shape pattern. All these radiographs were confirmed by an expert of the field.

\section{Discussion}

This study offers in vitro and in vivo experimental evidences that the CR extract and ME fraction of $Z$. officinale show exceptional anticariogenic potential. The GC- MS analysis of these extracts showed that there are numerous phytochemicals that are common in CR extract and ME fraction, which could be accounted for ME fraction activity being comparable to that of CR extract.

From the results obtained, the MIC value of CR extract and ME fraction against $S$. mutans was quite significant [34]. Also, in kinetic killing assay, both these extracts resulted in a rapid decrease of bacterial viable counts even at low concentrations suggesting that these extracts can be delivered in low but effective concentrations in the oral cavity to inhibit dental caries.

Furthermore, it is well documented that adherence is one of the most important step in establishment of dental caries and its inhibition could be a strong step against the impairment of its virulence [35]. The sucrose-independent (SI) adherence is usually because of hydrophobic interactions between the cells and the adhering surface. As per 

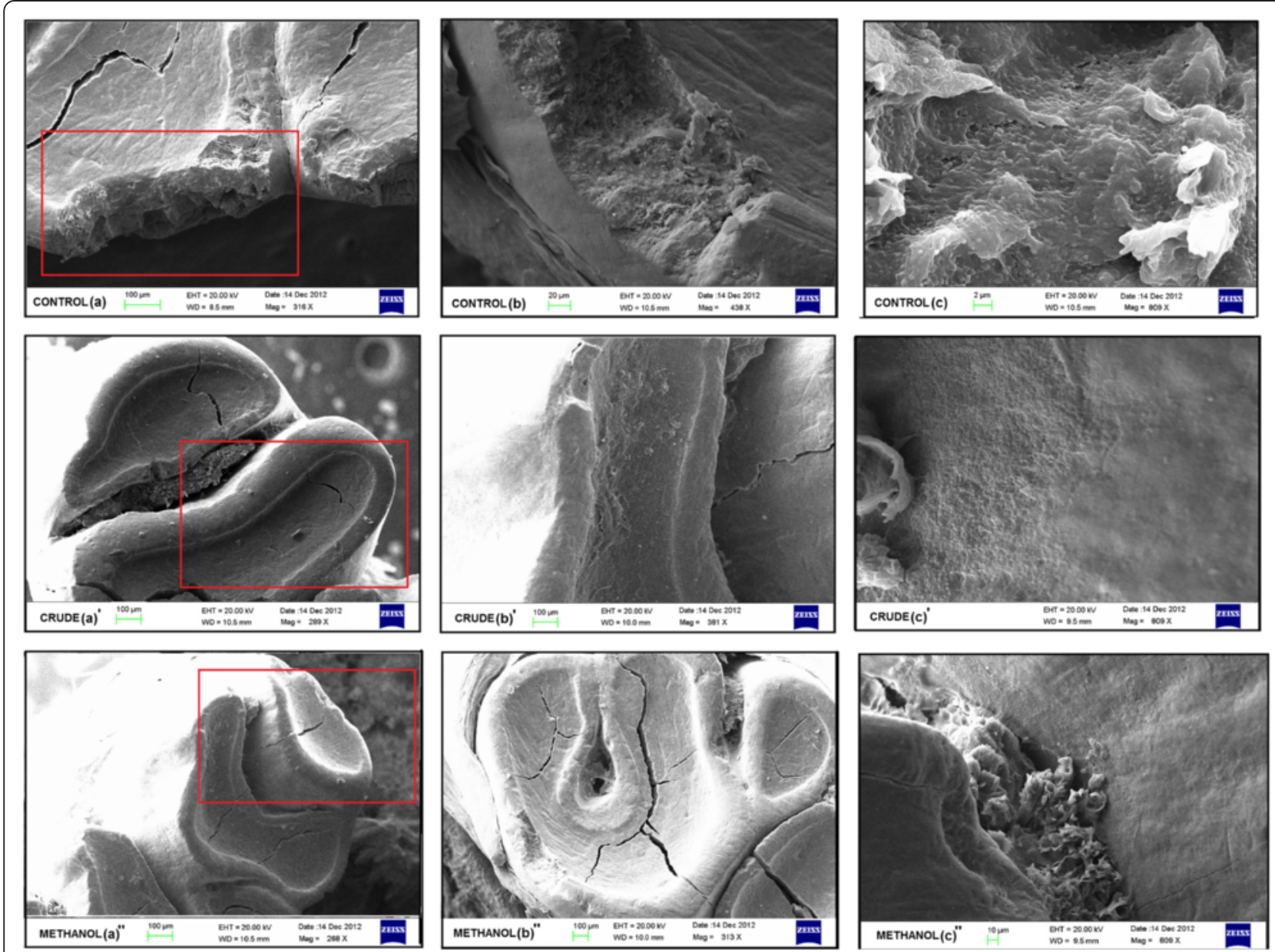

Figure 9 Scanning electron micrographs of aseptically removed rat teeth. SEM analysis of rats teeth to evaluate the effect of CR extract and ME fraction on development of caries and extent of demineralization in untreated (a) and groups treated with crude extract and methanolic fraction ( $\left.\mathbf{b}^{\prime} \boldsymbol{\&} \mathbf{b}^{\prime \prime}\right)$. Panels $\mathbf{c}, \mathbf{c}^{\prime} \& \mathbf{c}^{\prime \prime}$ show dental surface of the teeth to observe biofilm formation. Panel $\mathbf{b}$, $\mathbf{b}^{\prime}$ and $\mathbf{b}^{\prime \prime}$ shows the zoomed area focussed in red square of panel $\mathbf{a}, \mathbf{a}^{\prime}$ and $\mathbf{a}^{\prime \prime}$ respectively.

the results obtained, there is reduction in SI adherence as well as hydrophobicity. Because of the reduced hydrophobic interactions between the cells and the surface, bacteria were unable to adhere. Thus, the reduction in hydrophobicity could be directly co- related with the reduction in SI adherence. Sucrose dependent adherence, on the other hand, is mediated via synthesis of glucans. GTFase is the enzyme responsible for the conversion of sucrose to sticky glucans, which promotes the adherence of $S$. mutans to the surface of the tooth. Hence, SD adherence depends upon glucan production. It is evident from the results that $\mathrm{CR}$ extract and ME fraction reduced the glucan synthesis in addition to SD adherence, as flavonoids are known to have anti- GTFase activity [36]. As higher amount of insoluble glucans in the matrix is directly associated with increased cariogenicity in humans [3], the inhibition he synthesis of water insoluble glucan (as per the results obtained) will lead to an altered exopolysaccharide matrix resulting in ineffective adherence. Another important event in pathogenesis of $S$. mutans is the formation of biofilm which is also mediated by glucans. The reduction in water insoluble glucan (WIG) will result in a considerable reduction of biofilm formation as it will interfere with the pathogenesis by disrupting physical integrity and stability, reducing the availability of binding sites for S. mutans [37]. As per the results obtained, $\mathrm{CR}$ extract and ME fraction reduced biofilm formation during different growth phases i.e., in initial attachment phase $(6 \mathrm{~h})$, active accumulated phase $(12 \mathrm{~h})$, initial plateau accumulated phase $(20 \mathrm{~h})$ and plateau accumulated phase (24 h), suggesting not only the inhibition of biofilm formation but also its maturation at critical developmental stages. Hence, based on these results, it is apparent that $\mathrm{CR}$ extract and ME fraction could inhibit the GTF activity of $S$. mutans and thereby the bacterial adherence, signifying their potential to modulate the development and accumulation of $S$. mutans dental biofilms (monospecies). 

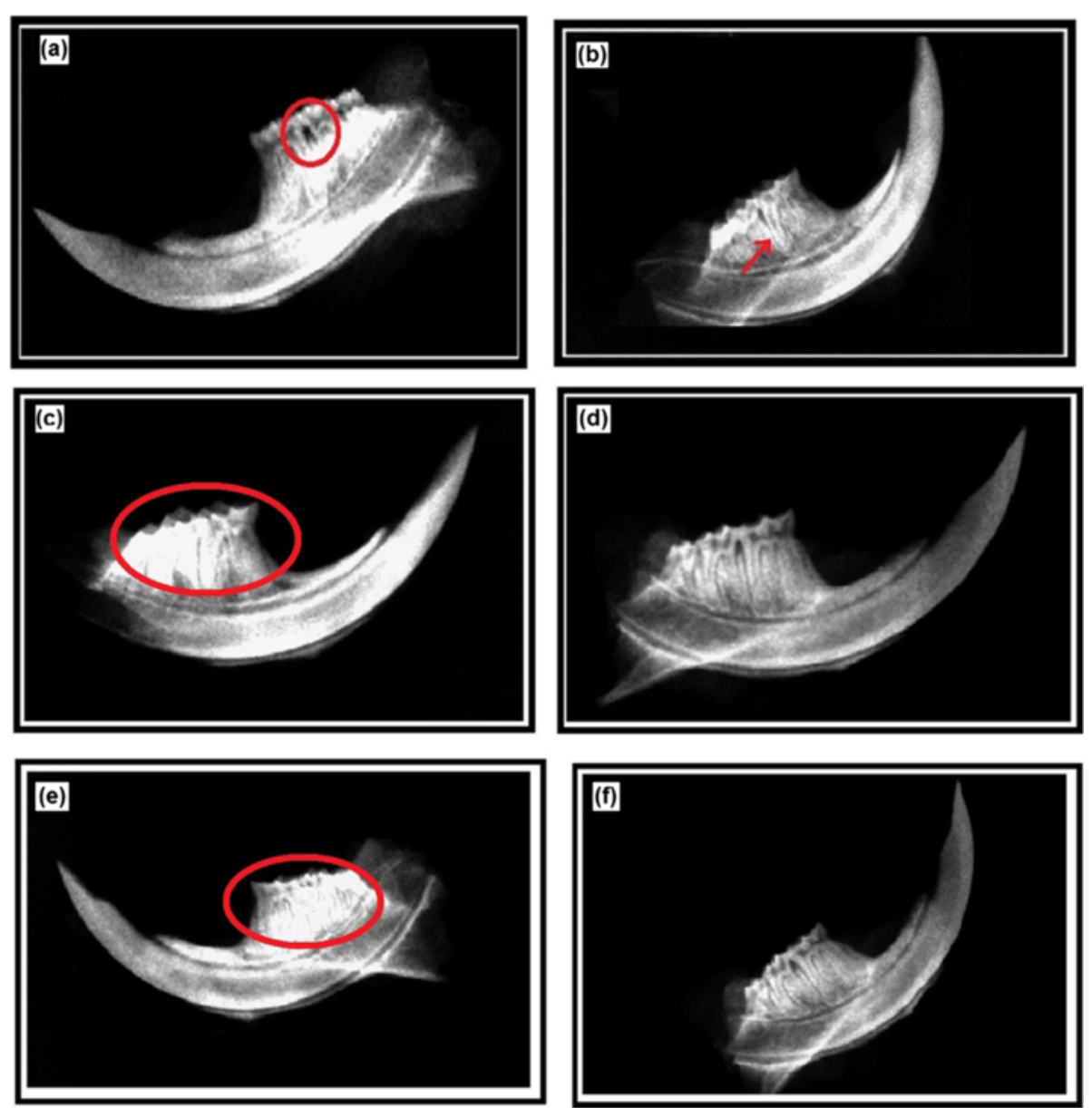

Figure 10 Digital radiographs of rat teeth. Digital radiographs of untreated $(\mathbf{a} \& \mathbf{b})$ and treated rat teeth with $C R$ extract $(\mathbf{c} \boldsymbol{\&} \mathbf{d})$ and methanolic fraction (e \& f) rat teeth to evaluate the anticariogenic effect of $C R$ extract and ME fraction.

The results obtained from glycolytic pH drop showed inhibitory activity of the extracts against acidogenicity, marked by a tremendous reduction in the initial and final rate of the $\mathrm{pH}$. This reduction in acidic value of $\mathrm{pH}$ could be directly co-related to the inhibition of the bacterial glycolytic enzymes. Furthermore, since the final $\mathrm{pH}$ values in glycolytic $\mathrm{pH}$-drop assay stand for acid tolerance [28], the reduction in these values indicate the disruption of aciduracity potential as well. S. mutans by fact, is an aciduric bacteria which can carry out glycolysis at extremely low $\mathrm{pH}$ values. This is because the bacteria are able to maintain $\mathrm{pH}$ homeostasis across the cell membrane, which maintain the cytoplasmic alkalinity [37]. This aciduracity is mainly attributed by F- ATPase proton pump by maintaining $\mathrm{pH}$ gradient across the membrane [37]. The reduction in F-ATPase proton pump function by $\mathrm{CR}$ extract and ME fraction is evident from the data obtained. Thus, its suppression may contribute to rise in cytoplasmic acidity resulting in decreased acid adaptation. Cytoplasmic acidity will therefore lead to the impairment of functioning of a series of enzymes involved in physiological processes like glycolysis, cell persistence, IPS and EPS production, resulting in potential mortal effect on S. mutans [25].

The inhibitory role of the extracts (CR and ME) against Ag I/II or SpaP showed a moderate suppression of protein expression. As this surface antigen is known to critically induce bacterial adhesion [3], its reduction could be an alternate approach to combat dental caries.

The CLSM and scanning electron micrographs demonstrated the difference in architecture of the biofilm in control and treated samples. The apparent scattering of cells in treated samples can be related to the inhibition of glucan synthesis. This observation was further supported by the scanning electron microscopy. Unlike the untreated cells, entrenched in the sticky glucan pool, the treated cells had only traces of glucan resulting in cell dispersion and reduced cell to cell signalling, consequently obliterating the structural integrity of a biofilm. The reduction in the glucan synthesis however also confirmed the inhibition of GTFs activity. 
Additionally, the expression profile showed that entire set of virulent genes were down regulated in the presence of crude extract and methanolic fraction. Gene relA, is known to be involved in the oxidative stress and acid tolerance mechanisms of S. mutans [38] whereas, $\operatorname{brp} A$ plays a critical role in formation of biofilm and its structural integrity. The repression of these genes will therefore lead to impaired acid tolerance and major structural defects in biofilm formation and integrity respectively, resulting in despaired virulence expressions. In addition, gtfC, catalyse the synthesis of water soluble and water insoluble glucan from sucrose. The reduction in the expression of this gene will thereby suppress the cascades involved in biofilm formation, cell wall integrity, adhesion promotion and surface biogenesis. The regulatory gene $\operatorname{comDE}$, is a part of the quorum-sensing cascade of $S$. mutans [38]. The downregulation of this gene will attenuate the internal communication system utilized by the bacteria to alter their gene expression at a critical cell density, which may even lead to cell death.

Hence, the overall effect of CR extract and ME fraction is evidently anticariogenic as shown by in vitro studies. However, the complexity of the bacteria-host interaction leads us to the use of animal models, where caries lesions can be studied under controlled conditions. In vivo studies demonstrated that the daily topical exposure these extracts dramatically affected the ability of $S$. mutans to colonize on the tooth surfaces, consequently inhibiting the development of smooth surface caries and, to a lesser extent, sulcal surface carious lesions. The results obtained specify that the active compounds are available at efficacious concentrations in oral cavity despite of their brief exposure due to salivary clearance. It is known that the persistence of a therapeutic effect of topically applied agent in the oral cavity is a highly desirable in the development of chemotherapeutic approaches against dental caries [39]. The in vivo results (anticariogenic) may again be related to the effective inhibition of GTF activity and on bacterial glycolytic pathway which would reduce the pathogenicity of S. mutans in vivo. Our results are in harmony with a previous study which showed that a pronounced reduction in smooth-surface caries than the incidence of sulcal caries were observed in rats infected with $S$. mutans mutants defective in the production of either one or both Gtfs [40]. The in vivo effects of these extracts (CR and ME) are also validated with scanning electron micrographs and digital radiographs evidently showing reduced demineralization and a healthy pulp without any sequelae of dental caries (pulpitis). However, certain limitations can be overcome in the future studies that include the purification of pure compounds from the extracts. Also, instead of studying only S. mutans (monospecies), certain other oral micro- organisms (like A. viscosus, L. acidophilus, S. salivarius, C. albicans, $L$. lactis) that play a significant role in the prevalence of dental caries can also be studied.

However, as compared to our previous study which evaluated the potential of Emblica officinalis against cariogenic properties of S. mutans [3], the present study bears an upper hand. All the cariogenic factors that were evaluated in both these studies were evidently more reduced by Z.officinale than E. officinalis. Additionally, this study proves to be novel over the previous study [3], as it is extended to in vivo studies validating the in vitro results that showed $Z$. officinale to be a potential anticariogenic agent.

Hence, the study clearly indicates that CR extract and ME fraction of $Z$. officinale possess immense cariostatic potential. Furthermore, its non-toxic nature makes it more alluring for the development of novel anti-caries therapeutic agent.

\section{Conclusion}

This study has investigated the effect of crude extract and methanolic fraction of $\mathrm{Z}$. officinale against virulence properties of $S$. mutans. It reflects a prospective role of $Z$. officinale as a potential therapeutic agent against virulence traits of $S$. mutans. Hence, it can be a promising prophylactic therapeutic agent for dental caries.

\section{Additional files}

Additional file 1: Nucleotide sequences of primers used in this study. Additional file 2: List of ligands identified from $Z$. officinalis Crude extract and Ethanolic fraction using GC-MS analysis.

Additional file 3: Recovery of Streptococcus mutans on the following weeks after inoculation $\left(\times 10^{4} \mathrm{CFU}\right)$.

\section{Competing interests}

The authors declare that they have no competing interests.

\section{Authors' contributions}

SH performed the majority of the experiments analyzed the data and drafted the manuscript. MD performed a part of methodology and coordinated its drafting in the manuscript. AUK provided mentorship and initiated the project and critically reviewed the manuscript. All authors read and approved the final manuscript.

\section{Acknowledgements}

This study was supported by internal funds of IBU, AMU and ICMR grant no. 59/6/2009/BMS/TRM to AUK. Authors are also grateful to Dr. Saif Khan of Z. A Dental College, Aligarh for helping in comprehension of the digital radiographs. Also, thanks is due to Dr. Rajat Pratap Singh (Gentle Dental Home, Aligarh) for providing the facility of Digital Radiography. I also acknowledge the efforts of Dr. Shahper N Khan for critical proof reading of the manuscript.

Received: 25 April 2014 Accepted: 11 December 2014 Published online: 16 January 2015

\section{References}

1. Hardie JM: Oral microbiology: current concepts in the microbiology of dental caries and periodontal disease. Br Dent J 1992, 172:271-281.

2. Loesche WJ: Role of Streptococcus mutans in human dental decay. Microbiol Rev 1986, 50:353-380. 
3. Hasan S, Danishuddin M, Adil M, Singh K, Verma PK, Khan AU: Efficacy of $E$. officinalis on the Cariogenic Properties of Streptococcus mutans: A Novel and Alternative Approach to Suppress Quorum-Sensing Mechanism. PLoS One 2012, 7:e40319.

4. Marsh PD: Oral ecology and its impact on oral microbial diversity. In Oral bacterial ecology: the molecular basis. Edited by Kuramitsu HK, Ellen RP. Bymondham, Norfolk, United Kingdom: Horizon Scientific Press; 2000.

5. Donlan RM, Costerton JW: Biofilms: survival mechanisms of clinically relevant microorganisms. Clin Microbiol Rev 2002, 15:167-193.

6. Marsh PD, Bradshaw DJ: Dental plaque as a biofilm. J Ind Microbiol 1995, 15:169-75.

7. Kuramitsu H: Virulence factors of mutans streptococci: role of molecular genetics. Crit Rev Oral Biol Med 1993, 4:159-176.

8. Koo H, Hayacibara MF, Schobel BD, Cury JA, Rosalen PL, Park YK, Vacca-Smith AM, Bowen WH: Inhibition of Streptococcus mutans biofilm accumulation and polysaccharide production by apigenin and tt-farnesol. J Antimicrob Chemother 2003, 52:782-789.

9. Bowden GH, Hamilton IR: Survival of oral bacteria. Crit Rev Oral Biol Med 1998, 9:54-85.

10. Featherstone JDB: Remineralization, the natural caries repair process-the need for new approaches. Adv Dent Res 2009, 21:4-7.

11. Featherstone JDB: Prevention and reversal of dental caries: role of low level fluoride. Community Dent Oral Epidemiol 1999, 27:31-40.

12. Ribeiro DA, Bazo AP, da Silva Franchi CA, Marques ME, Salvadori DM: Chlorohexidine induces DNA damage in rat peripheral leukocytes and oral mucosal cells. J Periodontal Res 2004, 39:358-61.

13. Jeon JG, Rosalen $\mathrm{PL}$, Falsetta $\mathrm{ML}$, Koo $\mathrm{H}$ : Natural products in caries research: Current (limited) knowledge, challenges and future perspective. Caries Res 2011, 45:243-263.

14. Ferrazzano GF, Amato I, Ingenito A, Zarrelli A, Pinto G, Pollio A: Plant polyphenols and their anti-cariogenic properties: $A$ review. Molecules 2011, 16:1486-1507.

15. Jeena K, Liju VB, Kuttan R: Antioxidant, anti-inflammatory and antinociceptive activities of essential oil from ginger. Indian J Physiol Pharmacol 2013, 57:51-62.

16. Jeena K, Liju VB, Viswanathan R, Kuttan R: Antimutagenic Potential and Modulation of Carcinogen-Metabolizing Enzymes by Ginger Essential Oil. Phytother Res 2013. doi:10.1002/ptr.5064.

17. Abdel-Azeem AS, Hegazy AM, Ibrahim KS, Farrag AR, El-Sayed EM: Hepatoprotective, Antioxidant, and Ameliorative Effects of Ginger (Zingiber officinale Roscoe) and Vitamin E in Acetaminophen Treated Rats. J Diet Supp/ 2013, 10:195-209.

18. Khan R, Zakir M, Afaq SH, Latif A, Khan AU: Activity of solvent extracts of Prosopis spicigera, Zingiber officinale and Trachyspermum ammi against multidrug resistant bacterial and fungal strains. J Infect Dev Ctries 2010, 4:292-300.

19. Fatima S, Faroogi AHA, Kumar R, Kumar TRS, Khanuja SPS: Antibacterial activity possessed by medicinal plants used in tooth powders. J Med Arom PI Sci 2000, 22:187-189.

20. Islam TH, Azad AHB, Akter S, Datta S: Antimicrobial activity of medicinal plants on Streptococcus mutans, A Causing Agent Of Dental Caries. J Eng Res Tech 2012, 1:121-126

21. Islam B, Khan SN, Naeem A, Sharma V, Khan AU: Novel effect of plant lectins on the inhibition of Streptococcus mutans biofilm formation on saliva-coated surface. J Appl Microbiol 2009, 106:1682-1689.

22. Koo H, Rosalen PL, Cury JA, Park YK, Bowen WH: Effects of compounds found in propolis on Streptococcus mutans growth and on glucosyltransferase activity. Antimicrob Agents Chemother 2002, 46:302-1309.

23. Hamada S, Torii M: Effect of sucrose in culture media on the location of glucosyltransferase of Streptococcus mutans and cell adherence to glass surfaces. Infect Immun 1978, 20:592-9.

24. Loo CY, Corliss DA, Ganeshkumar N: Streptococcus gordonii biofilm formation: identification of genes that code for biofilm phenotypes. J Bacterio/ 2000 182:1374-82.

25. Hasan S, Singh K, Danisuddin M, Verma PK, Khan AU: Inhibition of Major Virulence Pathways of Streptococcus mutans by Quercitrin and Deoxynojirimycin: A Synergistic Approach of Infection Control. PLoS One 2014, 9:e91736.

26. Dubois M, Gilles KA, Hamilton JK, Rebers PA, Smith F: Colorimetric method for determination of sugars and related substance. Anal Chem 1956, 28:350-356.
27. Martin MA, Pfaller MA, Massanari RM, Wenzel RP: Use of cellular hydrophobicity, slime production and species identification markers for the clinical significance of coagulase negative Staphylococcal isolates. Am J Infect Control 1989, 17:130-135.

28. Ban SH, Kim JE, Pandit S, Jeon JG: Influences of Dryopteris crassirhizoma extract on the viability, growth and virulence properties of Streptococcus mutans. Molecules 2012, 17:9231-44.

29. Bencini DA, Shanley MS, Wild JR, O'Donovan GA: New assay for enzymatic phosphate release: Application to aspartate transcarbamylase and other enzymes. Anal Biochem 1983, 132:259-264.

30. Sali A, Blundell TL: Comparative protein modelling by satisfaction of spatial restraints. J Mol Biol 1993, 234:779-815.

31. Laurie ATR, Jackson RM: Q-SiteFinder: an energy-based method for the prediction of protein-ligand binding sites. Bioinformatics 2005, 21:1908-1916.

32. Jones $G$, Willett $P$, Glen RC: Molecular recognition of receptor sites using a genetic algorithm with a description of desolvation. J Mol Biol 1995, 245:43-53.

33. Larson RM: Merits and modifications of scoring rat dental caries by Keyes' method. In Animal Models in Cariology. Microbiology Abstracts (special suppl.). Edited by Tanzer JM. Washington: IRL; 1981:195-203.

34. Rios $J$, Recio MC, Villar A: Screening methods for natural products with antimicrobial activity: A review of the literature. J Ethnopharmacol 1988, 23:127-149.

35. Matsumoto M, Minami T, Sasaki H, Sobue S, Hamada S, Ooshima T: Inhibitory effects of oolong tea extract on caries-inducing properties of mutans streptococci. Caries Res 1999, 33:441-445.

36. Prabu GR, Gnanamani A, Sadulla S: Guaijaverin- a plant flavonoid as potential antiplaque agent against Streptococcus mutans. J Appl Microbiol 2006, 101:487-495

37. $\mathrm{Xu} X$, Zhou $X D$, Wu CD: The tea catechin epigallocatechin gallate suppresses cariogenic virulence factors of Streptococcus mutans. Antimicrob Agents Chemother 2011, 55:1229-36.

38. Liu C, Worthington RJ, Melander C, Wu H: A new small molecule specifically inhibits the cariogenic bacterium Streptococcus mutans in multispecies biofilms. Antimicrob Agents Chemother 2011, 55:2679-87.

39. Koo H, Duarte S, Murata RM, Scott-Anne K, Gregoire S, Watson GE, Singh AP, Vorsad N: Influence of Cranberry Proanthocyanidins on Formation of Biofilms by Streptococcus mutans on saliva-coated apatitic surface and on dental caries development in vivo. Caries Res 2010, 44:116-126.

40. Yamashita Y, Bowen WH, Burne RA, Kuramitsu HK: Role of the Streptococcus mutans gtf genes in caries induction in the specific pathogen- free rat model. Infect Immun 1993, 61:3811-3817.

\section{Submit your next manuscript to BioMed Central and take full advantage of:}

- Convenient online submission

- Thorough peer review

- No space constraints or color figure charges

- Immediate publication on acceptance

- Inclusion in PubMed, CAS, Scopus and Google Scholar

- Research which is freely available for redistribution 